\title{
Cyclic Behavior of a Bamboo-Steel Hybrid Moment Frame with a Novel Energy Dissipation Connection
}

\author{
Zirui Huang ${ }^{1,3}$, Dongsheng Huang ${ }^{2 *}$, Yanhua Wang ${ }^{1}$, and Yan Feng ${ }^{1}$ \\ ${ }^{1}$ School of Civil Engineering, Southeast University, Nanjing \\ ${ }^{2}$ National Engineering Research Center of Biomaterials, Nanjing Forestry University, Nanjing, \\ China \\ ${ }^{3}$ Department of Environment and Civil Engineering, University of Alberta, Alberta, Canada \\ *Corresponding author's e-mail: dshuang@njfu.edu.cn
}

\begin{abstract}
This paper presents a novel bamboo/wood-steel hybrid frame which uses engineered bamboo products as beams and steel as columns. The beams and columns are jointed by an innovative connection which incorporates a steel hinge and two steel brackets to carry shear force and moment from the end of beam, respectively. The bracket consists of two segments, i.e. joint segment connected to beam and the other segment, which serves as energy dissipation panel (EDP), connected to the columns via a base panel. By this way, the connection can provide sufficient initial stiffness for serviceability requirements and excellent energy dissipation capacity for seismic performances. Lateral cyclic loading tests were conducted to investigate the seismic performances of the frame. It was found that hysteresis loops of the frame with energy dissipation joints show less pinching than that of frames with dowel- or bolt-type connections; by proper designing, the damage and failure of the frame can be restricted in the EDPs of connections, whereas virtually no damage was observed in the other components of the frame; the connection can provide more than $10 \%$ damping for the frame after the yielding of EDPs. Design method is also proposed in this paper.
\end{abstract}

\section{KEYWORDS}

Bamboo-steel hybrid frame; Energy dissipation joints; Cyclic behavior

\section{INTRODUCTION}

Engineered bamboo or wood products are the attractive renewable and environmentally friendly construction materials. Due to the concern of conventional construction materials putting significant strain on natural resources and creating gas emissions, bamboo and wood products are considered as an ideal alternative of conventional materials. Over the last decades, wood and bamboo products have been achieved great successful in low wood and bamboo buildings (Karacabey and Lum, 2014; Williams and Karacabey, 2016; Kermani, 1999; Lugt et al., 2006).

China has the largest plantation of bamboo forestry in the world but lacks wood reserve; hence wood harvest is strictly restricted. Therefore, more recently, bamboo products, usually parallel strand bamboo (PSB) and laminated bamboo (LVB) (D. Huang et al., 2015a; D. Huang 
et al., 2015b; D. Huang et al., 2013; Z. Huang et al., 2016), are innovated as an alternative of wood products to build low-rise buildings (Sharma et al., 2015). However, China has no enough land supply to support the low-rise buildings for so large populations, thus therefore, high-rise buildings are always being the major demand in real-estate marked. This gives rise to a great restriction of bamboo products in the application of construction engineering due to the relative lower strength and stiffness of bamboo products compared to steel and concrete.

Bamboo-steel hybrid structure provides a practical solution to extend bamboo products for multi- and high-rise building construction. By using steel as vertical components and engineered bamboo products as horizontal components, the limitation of the bamboo use in multi- and highrise buildings can be eliminated. Obviously, the design of the connection of bamboo-steel hybrid frame is the major concern to make the structure has good seismic performances. Generally, the ideal design of the frame is to control the damage and failure of the frame in the desire mode, and to make the frame have enough initial stiffness to meet the serviceability requirement and good ductility to consume the seismic energy input. Typically, there are two types of connections available, i.e., dowel-type and bolt-type connections, for wood or bamboo structures (Araki et al., 2011; Loss et al., 2016; Kharouf et al., 2003; Quenneville and Mohammad, 2011; Mohammad and Quenneville, 2001; Santos et al, 2013). The performances of these connections, however, cannot be well controlled because of the complicated damage mechanism (Dourdo et al., 2018).

This paper presents a novel bamboo-steel moment frame, which uses steel as columns and laminated veneer bamboo (LVB) as beams. A semi-rigid connection was designed for this steelLVB frames. The connection incorporates a hinge and a pair of top and seat brackets to carry shear force and moment from the connecting beam, respectively. Each bracket consists of two segments. One of the segments is the joint panel which is welded to a steel stub bolted to two sandwich beam panels. The other segment serves as energy dissipation panel (EDP), which is welded to a base panel through which the connection is fixed to the steel column; and the EDP is free of out-of-plane restrictions so that it can deformed freely perpendicular to its own plane. By this way, the connection behaves as a seesaw supported on a hinge which bears most of the shear force of the connected beam. The top and seat brackets restrict the rotation of the connection providing resistant moment and lateral stiffness for the frame, as shown in Fig.1(b). Furthermore, by an appropriate design and detailing, the first yielding of the frame can be confined to the EDPs while the other parts of the frame are protected when the frame is subjected to lateral load.

In order to understand the seismic performances of the steel-LVB hybrid frame, cyclic loading experiment for a full size one-storey frame was carried out. Damage and failure mode, hysteresis loops, and energy dissipation of the frame were investigated. Detail design of the connection and the design method were proposed according to the experimental results.
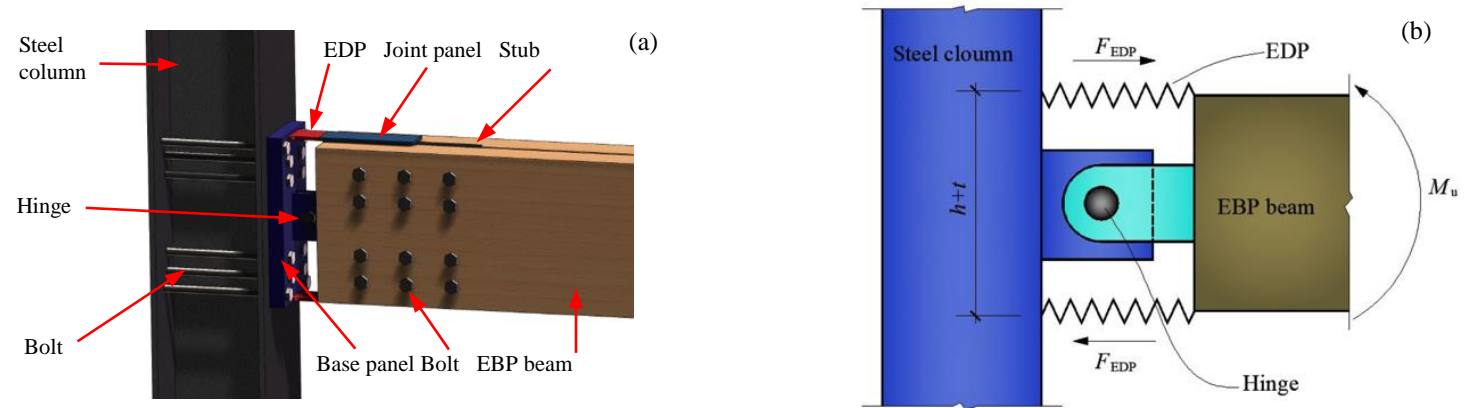

Figure 1. Moment connection for bamboo-steel moment frame; (a) details of proposed energy-dissipating connection; (b) working principle of the connection. 


\section{EXPERIMENTAL INVESTIGATION}

As it was aforementioned above, the frame connection with EDP was designed to avoid failure on beams, columns, and bolt-joints, which have less ductility and uncontrolled stiffness and strength. By proper designing, the stiffness and strength of the structure can be controlled as expected and the failure of the frame can be restricted in EDPs, which may provide good ductility and additional damp for the structure. In order to check this design philosophy, a fullsize bamboo-steel frame with EDP connections was employed to conduct cyclic loading test. The failure mode, hysteresis performance, and energy dissipation of the frame were studied.

\section{Specimens preparing}

The dimensions of test frames are presented in Fig. 2. H-profile steel with dimension of 300 $\mathrm{mm} \times 300 \mathrm{~mm} 10 \mathrm{~mm} \times 15 \mathrm{~mm}$ was employed to prepare frame columns; two LVB panels with same cross-section of $145 \mathrm{~mm} \times 127 \mathrm{~mm}$ was selected as the frame beam. The base panel of the connection was mounted on the column through 12 bolts of $20 \mathrm{~mm}$ diameters. The LVB panels were mounted on the two sides of joint panel of the connection, respectively, through 12 bolts of $22 \mathrm{~mm}$ in diameters. Fig. 2 schematically illustrates in details of the joint manner.

The strengths of all bolt joints were pre-checked to avoid joint premature failure before EDP yield. The steel of columns and connection are all Q-235, according China standard GB 500172017. The steel of columns and connection are all Q-235 grade. Mechanical properties of the steel and LVB were tested before experiment, which are collected in Table 1.

In order to check the strength of bolted joints, the maximum moment-bearing of the EDP connection was estimated. In the previous study conducted by Huang, the maximum momentbearing of EDP connection can be estimated by

$$
M_{u}=\eta f_{\mathrm{u}} b t(h+t)
$$

where, $f_{\mathrm{u}}$ is the ultimate strength of the EDP steel; $b$ and $t$ are the width and thickness of the EDP, respectively; $h$ is the clear space between the two EDPs; $\eta$ is the coefficient that represents the degree of partial yielding which depends on the EDP length-to-thickness ratio, and can be calculated by

$$
\eta= \begin{cases}0.978 & 6.6 \leq \lambda \leq 7.2 \\ 0.749+1.150 e^{-\frac{\lambda}{1.897}} & 7.2<\lambda \leq 16.0\end{cases}
$$

Where, $\lambda=l / t$, represents the length-to-thickness ratio of EDP, and $l$ is the length of EDP. The check of the strength of bolts joints are presented in Table 2.

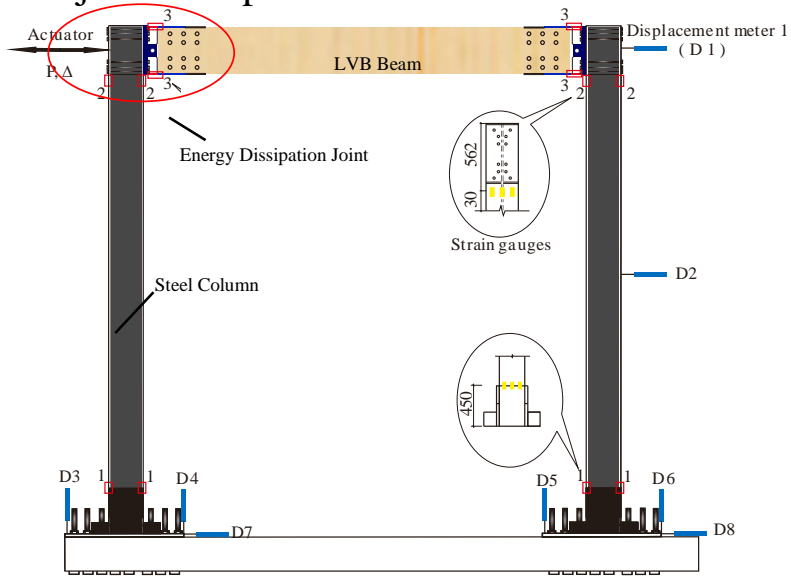

Figure 2. Details of the frame and locations of collecting points 
MOC SUMMIT / MAY 2019

Table 1. Mechanical properties of steel and LVB

\begin{tabular}{cccccc}
\hline Materials & Yield strength/MPa & Ultimate strength/MPa & Young's modulus/GPa & Poisson's ratio & Ratioofelongation \\
\hline EDP & 315.25 & 443.03 & 209 & 0.28 & 0.41 \\
Column & 272.55 & 438.73 & 217 & 0.28 & 0.32 \\
LVB & - & - & 8.26 & - & - \\
\hline
\end{tabular}

\section{Test procedure}

Test was performed in the Laboratory of Civil Engineering of Nanjing Forestry University. The hydronic-servo actuator was employed to apply load to the frame. The capacity and maximum movable distance of the actuator are $1000 \mathrm{kN}$ and $\pm 250 \mathrm{~mm}$, respectively. The actuator was jointed to the fame through a joint panel which was fixed on the top of frame column by 4 bolts. The feet of steel columns were fixed on the rigid ground of the laboratory through 4 bolts. In order to prevent out-of-plane distortion, a transverse support system was built at the two sides of the frame.

Table 2. Check of the strength of joint strength

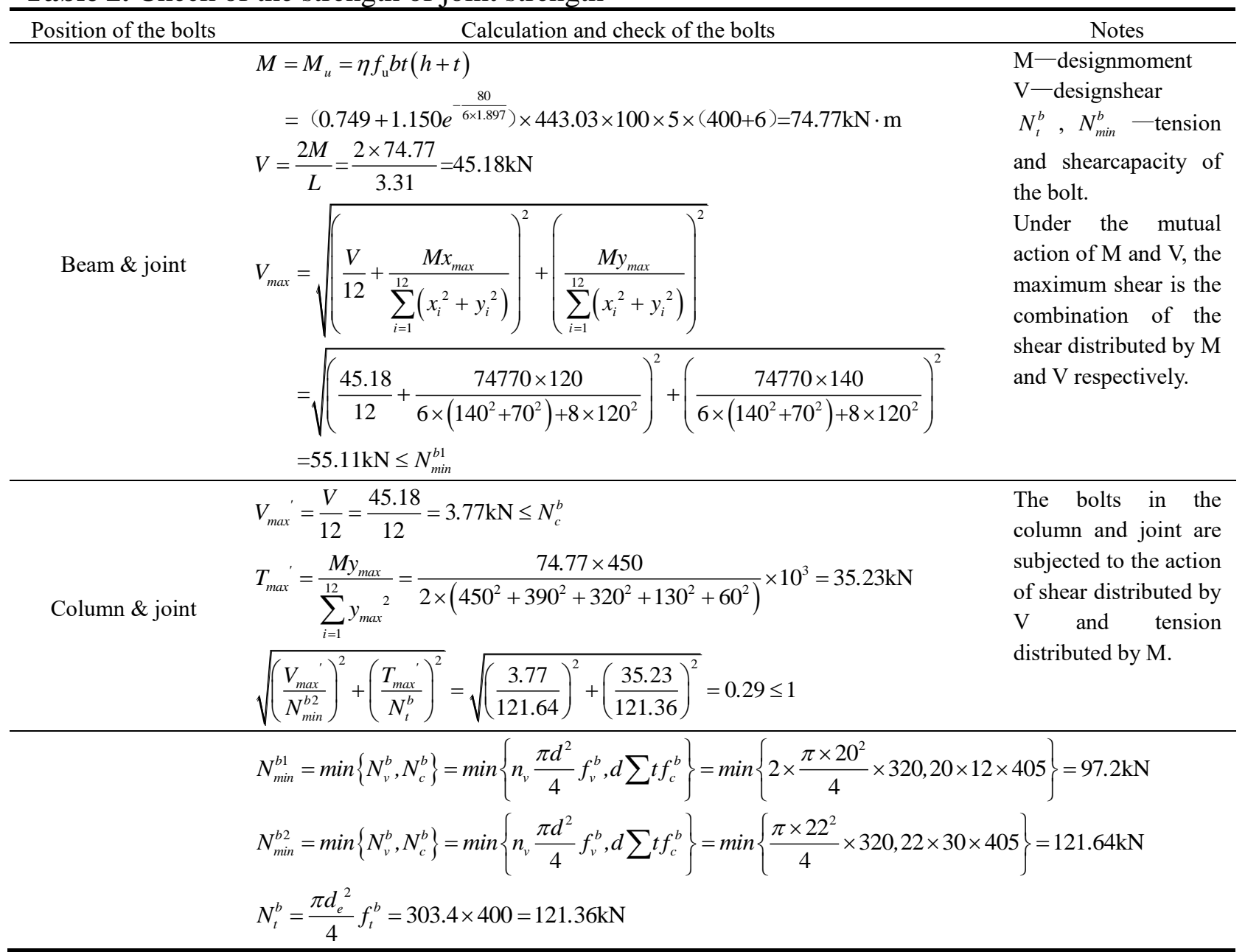

Preloading was conducted to check if all the bolt-joints were proper mounted and work well. Then unload the actuator to zero and reset the acquisition system. Load was controlled by the 
movement of actuator at the speed of $4 \mathrm{~mm} / \mathrm{min}$ before EDP yielding, while change to $0.2 \Delta$ $\mathrm{mm} / \mathrm{min}$ after the first yielding of the EDP takes place, where, $\Delta$ represents the top displacement of first yielding of the frame. Three loading-unloading cycles were carried out for each loading grade after first yielding took place.

The displacements of the top of the frame, middle height, and the bottom of the column were monitored, and the strains of EDPs were measured. The locations of displacements sensors and strain gauges are presented in Fig. 2. External load was measured by loading cell at the front of actuator. All the measured quantities were simultaneously recorded by TDS 530 data acquisition.

\section{Test results}

\section{Failure mode}

It was as expected that the damage and failure were restricted in the energy dissipation panel (EDP). The first yielding took place at the middle of EDP when the lateral displacement at the top of the frame reached about $10 \mathrm{~mm}$ and the corresponding external load was $36.1 \mathrm{kN}$. Then the successive yielding of the other monitoring position can be observed with the augment of lateral load. When the lateral displacement at the top of the frame reached $25 \mathrm{~mm}$, the strains at all the monitoring positions exceeded the proportional limit indicating that the most of EDP yielded. Pronounced deformation of the EDP can be observed and the global load-displacement profile of the frame reached its summit point. At this moment, the external load applied on the frame was $100 \mathrm{kN}$. In the next loading process, the external load decreased as the lateral displacement increasing. When the lateral displacement reached $45 \mathrm{~mm}$, the middle of the EDP at the far-end of the actuator cracked, and when the lateral displacement reached $50 \mathrm{~mm}$, the middle of the other EDP at the close-end of the actuator cracked. The external load significantly declined indicated that the frame lost its load-carrying capacity. The failure mode is graphically illustrated in Fig. 3.
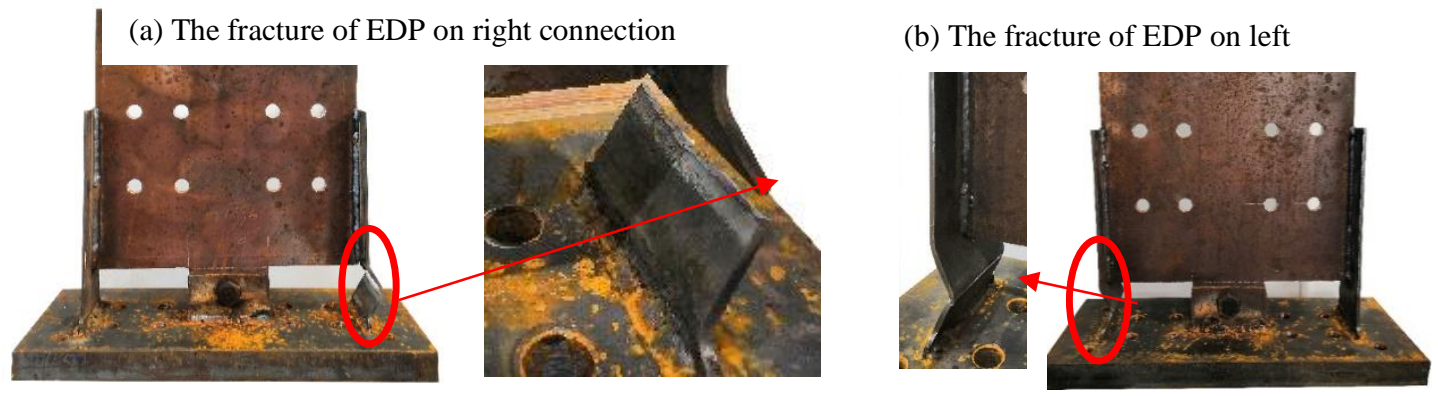

Figure 3. Failure mode;(a) failure of the right connection;(b) failure of the left connection

\section{Hysteresis loops}

The hysteresis loop of the frame is presented in Fig. 4a. The envelop profile was obtained from the first load cycle for each loading grade, as shown in Fig. 4b. Compared to the doweltype or bolt-type connections (Oudjene et al., 2017; Zhou et al., 2019), the pitch of hysteresis loop was significantly improved by using the EDP connection. This means the frame with EDP connection has better energy dissipation performance than the frame with conventional bolt- or dowel-type connections. The characteristics of the loop and the envelop profile can be summarized as follows: (1) at the beginning of loading, the response of the frame exhibited linear behavior, and the initial lateral stiffness, proportional external load and the corresponding 
lateral displacement were $4406 \mathrm{kN} / \mathrm{m}$; (2) once the external load exceeds the proportional limit, damage onset began on one or two of the EDPs, and the damage area continuously expanding with the load increasing, leading to continuous stiffness degradation till one of the EDP cracked. The external load reached it maximum value and the load-displacement profile went up to is summit point at the end of this stage; (3) the load-displacement profile went down after pass through its summit till the other EDP cracked, the critical symbol of the failure of frame.

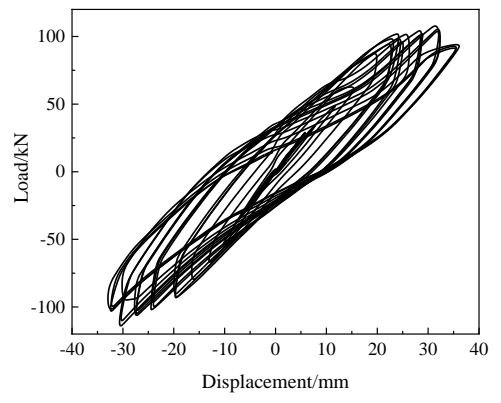

(a)

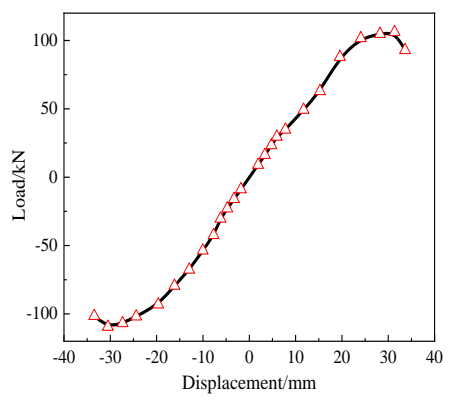

(b)

Figure 4. Experiment results (a) hysteresis loop; (b) skeleton curves

\section{Damp and ductility}

The ductility ratio of the frame was estimated in terms of the Equivalent Energy ElasticPlastic (EEEP) procedure addressed in ASTM E2126, as illustrated in Fig. 8. The procedure can be summarized as follows: a line is first drawn, going through the origin and the point on the envelope curve where the external load equals to $40 \%$ maximum load. The yield point was determined by equating the area under the bi-linear EEEP response to the area under the test envelope curve, referring to Fig. 5. This was achieved by adjusting the horizontal line until the equivalent area criterion was met. The ductility ratio is expressed as $\mu=\Delta_{y} / \Delta_{u}$, where, $\Delta_{y}$ and $\Delta_{u}$ are defined as yield and ultimate displacement, respectively. For the envelope with post-peak declining branch, $\Delta_{\mathrm{u}}$ is the rotation corresponding to the 0.8 maximum load.

The initial lateral stiffness of the frame is defined as stiffness before the first yielding takes place; hence it can be estimated by $K_{\text {initial }}=P_{\mathrm{y}} / 4$, where, $P_{\mathrm{y}}$ is the first yield load.

The values of first yielding load and associated displacement, ultimate load and associated displacement, initial stiffness, and ductility of the frame are presented in Table 3.

Table 3. Experimental results

\begin{tabular}{ccccc}
\hline $\begin{array}{c}\text { Yield } \\
\text { load } / \mathrm{kN}\end{array}$ & $\begin{array}{c}\text { Yield } \\
\text { displacement } / \mathrm{mm}\end{array}$ & $\begin{array}{c}\text { Ultimate } \\
\text { load } / \mathrm{kN}\end{array}$ & $\begin{array}{c}\text { Ultimate } \\
\text { displacement } / \mathrm{mm}\end{array}$ & $\begin{array}{c}\text { Initial stiffness } / \mathrm{kN}^{*} \mathrm{~m}^{-} \\
1\end{array}$ \\
\hline 103.32 & 23.45 & 95.60 & 34.20 & 4406 \\
\hline
\end{tabular}

The energy dissipation of the frame is measured by the area of one hysteresis loop under a loading-unloading cycle. The damping ratio stands for the ratio of engineer dissipated in one loop to the total strain energy in one loading-unloading cycle, and in can be calculate by

$$
\varsigma=\frac{1}{2 \pi} \frac{S_{\text {Loop }}}{S_{\triangle \mathrm{ODE}}+S_{\triangle \mathrm{OAF}}}
$$


Where, $S$ represents area, and the subscripts, $\triangle \mathrm{ODE}$ and $\triangle \mathrm{OAF}$, stand for the triangles ODE and OAF, respectively, referring to Fig. 6. By this way, the damping ratio of the can be obtained, which is $14.1 \%$.

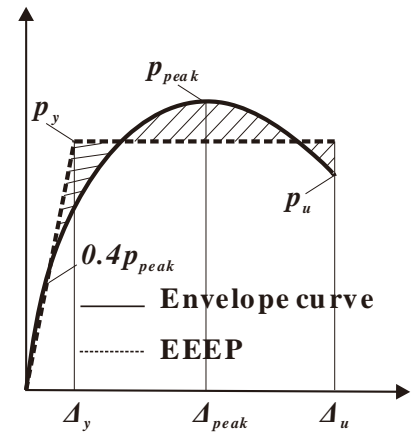

Figure 5. Ductility ratio

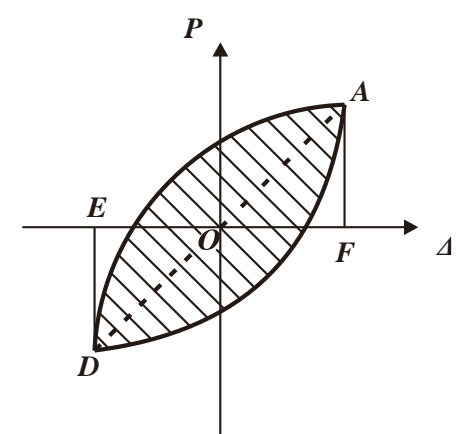

Figure 6. Damping ratio

\section{CONCLUSIONS}

A cyclic loading experiment for bamboo-steel frame of connections with energy dissipation panel (EDP) was conducted. The performances of the tested specimen indicated that bamboosteel hybrid frame can be a good solution to extend engineered bamboo composites to multi- or high-rise building application. By proper designing, the damage and failure, including their position and mode, can be controlled as expected. The major conclusions can be achieved as follows.

The connection of EDP makes the load-bearing capacity, initial stiffness, and successive stiffness of the frame can be controlled as expected by proper select the ratio of length-tothickness of EDP. Because the damage and failure are restricted in EDP, the bolt joints in the frame are prevented from damage. This makes the frame more designable and reliable.

The pitch of hysteresis loops of conventional dowel-type and bolt-type moment connections is improved; therefore. The damping ratio of the bamboo-steel frame can reachmore than $10 \%$. This makes the structure may significantly mitigate the seismic responses during the post yielding of EDPs. Therefore, the connection is not only a joint component, but also an energy dissipation device for seismic mitigation.

\section{ACKNOWLEDGEMENTS}

The study was supported by National Intensive Research Project, 2017YFC0703500, which was provided by the Ministry of Science and Technology, China. Their support is gratefully acknowledged.

\section{REFERENCES}

Karacabey, E., Lum, C. (2014). "Technical guide for the design and construction of tall buildings in Canada." FPInnovations.

Williams, L. E., Karacabey, E. (2016). "Application of analysis tools from NEWBuilds research network in design of high-rise wood buildings." NSERC Strategic Research Network on Innovation Wood Products and Building Systems (NEWBuilds), Canada. 
Kermani A. (1999). "Structural timber design.” Blackwell Science Ltd., a Blackwell Publishing Company, USA.

Lugt, P., Dobblesteen, A.A.J.F., Janssen, J.J.A. (2006). "An environment, economic and practical assessment of bamboo as a building materials for supporting structures." Construction and Building Materials, 20: 648-656.

Huang, D., Bian, Y., A., Zhou, Sheng, B. (2015). "Experimental study on stress-strain relationships and failure mechanisms of parallel strand bamboo made from Phyllostachys." Construction and Building Materials, 77: 130-138.

Huang, D., Bian, Y., Huang, DM., A. Zhou, Sheng, B. (2015). "An ultimate-state-based mode for inelastic analysis of intermediate slenderness PSB columns under eccentrically compressive load." Construction and Building Materials, 94: 306-314.

Huang, D., Zhou, A., Bian, Y. (2013). "Experimental and analytical study on the nonlinear bending of parallel strand bamboo beams." Construction and Building Materials, 44: 585592.

Huang, Z., Chen, Z., Huang, D., Zhou, A. (2016). "The ultimate load-carrying capacity and deformation of laminated bamboo hollow decks: Experimental investigation and inelastic analysis." Construction and Building Materials, 117: 190-197.

Sharma, B., Gatoo, A., Bock, M., Ramage, M. (2015). "Engineered bamboo for structural applications." Construction and Building Materials, 81: 66-73.

Araki, Y., Endo, T., Twata, M. (2011). "Feasibility of improve slotted bolted connection for timber moment frames." Journal of Wood Science, 247-253.

Loss, C., Piazza, M., Zandonini, R. (2016). "Connections for steel-timber hybrid prefabricated buildings: Part I: Experimental tests." Construction and Building Materials, 122: 781-795.

Kharouf, N., McClure, G., Smith, I. (2003). "Elasto-plastic modeling of wood bolted connections." Computers and Structures, 81: 747-754.

Quenneville, J.H.P., Mohammad, M. (2011). "Design method for bolted connections loaded perpendicular-to-grain.” Canadian Journal of Civil Engineering, 29: 949-959.

Mohammad, M., Quenneville, J.H.P. (2001). "Bolted wood-steel and wood-steel-wood connections: verification of new design approach." Canadian Journal of Civil Engineering, 28: $245-263$.

Santos, C.L., Jesus, A.M.P., Morais, J.J.L., Fontoura, B.F.C. (2013). "An experimental compression of strengthening solutions for dowel-type wood connections." Constructions and Building Materials, 46: 114-127.

Dourdo, N., Silva, F.G.A., Moura, M.F.S.F. (2018). "Fracture behavior of wood-steel joints under quasi-static loading." Construction and Building Materials, 176: 14-23.

Oudjene, M., Tran, V. D., Khelifa, M. (2017). "Cyclic and monotonic responses of double shear single dowelled timber connections made of hardwood species: Experimental investigations." Construction and Building Materials, 132: 188-195.

Zhou, L., Chui, Y-H, Ni, C. (2019). "Numerical study on seismic force modification factors of hybrid light wood frame structures connected to a tiff core." Engineering Structures, 183: 874-882. 